\title{
Polymer-Specific Modeling of the Environmental Emissions of Seven Commodity Plastics As Macro- and Microplastics
}

\author{
Delphine Kawecki ${ }^{\dagger}$ and Bernd Nowack* ${ }^{\dagger} \dagger$
}

${ }^{\dagger}$ Empa - Swiss Federal Laboratories for Materials Science and Technology, Technology and Society Laboratory, Lerchenfeldstrasse 5, CH-9014 St. Gallen, Switzerland

\section{Supporting Information}

\begin{abstract}
Plastic has been identified as an emerging contaminant in aquatic and terrestrial ecosystems. Uncertainties remain concerning the amounts present in the environment and the main responsible sources. In this study, the emissions of macro- and microplastics have been mapped for seven polymers in Switzerland. The modeling is based on a complete analysis of the flows from production and use to end-of-life using probabilistic material flow analysis. We estimate that $94 \pm 34$ $\mathrm{g} /$ capita/year of low-density polyethylene, $98 \pm 50 \mathrm{~g} / \mathrm{cap} / \mathrm{a}$ of high-density polyethylene, $126 \pm 43 \mathrm{~g} / \mathrm{cap} / \mathrm{a}$ of polypropylene, $24 \pm 13 \mathrm{~g} / \mathrm{cap} / \mathrm{a}$ of polystyrene, $16 \pm 12 \mathrm{~g} / \mathrm{cap} / \mathrm{a}$ of expanded polystyrene, $65 \pm 36 \mathrm{~g} / \mathrm{cap} / \mathrm{a}$ of polyvinyl chloride, and $200 \pm$

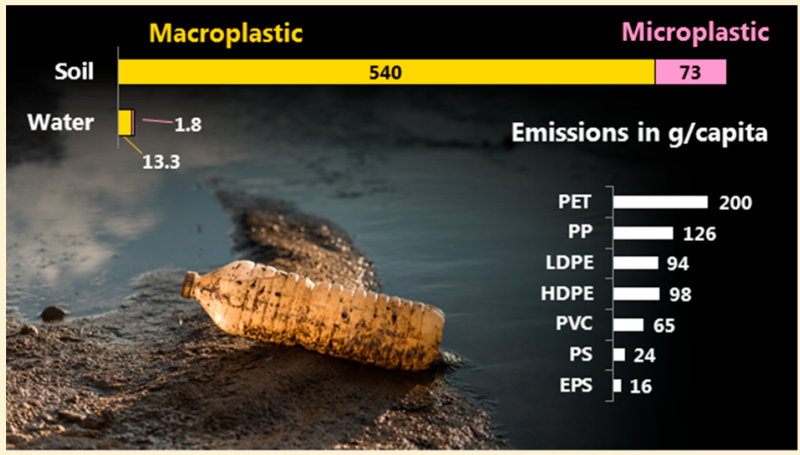
$120 \mathrm{~g} / \mathrm{cap} / \mathrm{a}$ of polyethylene terephthalate enter the Swiss environment. All polymers combined, $540 \pm 140$ and $73 \pm 14 \mathrm{~g} / \mathrm{cap} / \mathrm{a}$ are emitted into soil as macroplastics and microplastics, respectively, and $13.3 \pm 4.9$ and $1.8 \pm 1.1 \mathrm{~g} / \mathrm{cap} / \mathrm{a}$ are emitted into freshwater as macroplastics and microplastics, respectively. The leading emission pathway is littering for both terrestrial and aquatic environments. Construction, agriculture, and pre- and postconsumer processes cause important emissions of microplastics into soils, and postconsumer processes, textiles, and personal care products release most of the microplastics into waters. Because mass flows into soils are predicted to be 40 times larger than those into waters, more attention should be placed on this compartment. Our work also highlights the importance of referring to specific polymers instead of just "plastics".
\end{abstract}

\section{INTRODUCTION}

Microplastics (MP) have been reported in numerous freshwater systems in Europe, ${ }^{1-3}$ North America, ${ }^{4}$ Africa, ${ }^{5}$ Asia, ${ }^{6-8}$ both in densely populated areas $^{9}$ and remote systems. ${ }^{10}$ The presence of MP in soil is not as well documented as it is in freshwater since accurate methods for measuring MP concentrations in soil are still being developed; ${ }^{11-13}$ however, first estimates hint that burdens in soil may be considerable. ${ }^{14,15}$ MP have been reported in soils where sludge has been applied ${ }^{16}$ but also in areas with reduced direct human impacts. ${ }^{11}$ The main sources of MP to soil have been suggested to be compost and sludge application onto land, mulching plastics, littering, street runoff, and atmospheric deposition. ${ }^{1}$ Emissions to outdoor and indoor air have so far only been marginally addressed. ${ }^{18}$

The risk associated with MP is currently under debate $\mathrm{e}^{19-22}$ due to challenges arising in both hazard and exposure assessments. Current preliminary risk assessments predict little to no risk on average in marine ${ }^{23}$ and freshwater ${ }^{24}$ environments. In order for science to support actions from policy makers and citizens, a solid assessment of the present degree of pollution needs to be undertaken. MP emission assessments have been performed for Norway, ${ }^{25}$ Denmark, ${ }^{26}$ Germany, ${ }^{27,28}$ Sweden, ${ }^{29}$ Europe, $^{30}$ and the whole world. ${ }^{31}$ The receiving environmental compartment is sometimes not mentioned, ${ }^{25,28}$ or the focus is only on aquatic environments. ${ }^{26,27,29-31}$ Existing estimates for soil burdens are only preliminary and call for more precise assessments. ${ }^{17,32} \mathrm{MP}$ originating from macroplastic fragmentation are often outside of the scope of published MP-release studies ${ }^{26,29-31}$ or based on a rough estimate of the fraction of mismanaged waste. ${ }^{25,27}$ In one instance, the method of quantifying release remains unclear. ${ }^{28}$ Some published emission assessments have focused entirely on the release of macroplastic to the oceans, ${ }^{33,34}$ likewise based on roughly estimated fractions of mismanaged waste. ${ }^{35}$ To this day, large segments of the emission pathways are not wellknown, ${ }^{32}$ since data on specific release processes is scarce and subject to high variability.

To the best of our knowledge, no release model has systematically investigated the material composition of the emission flows. The distinction between different polymers for the exposure assessment is needed for several reasons. First, a risk assessment should ideally distinguish between individual

Received: May 15, 2019

Revised: June 19, 2019

Accepted: June 20, 2019

Published: July 9, 2019 
materials, since toxicities may be different depending on the material itself and the additives included. Since release pathways may also be very different depending on the lifecycle of the material, ${ }^{36}$ the exposure is also polymer dependent. Second, if fate models are to be developed, a differentiation between lower and higher material densities needs to be made. At last, for the implementation of the MP release into life cycle inventories (LCI), a distinction between material and life-cycle stage is needed.

The goal of this study is therefore to quantify the emissions of different plastics based on a complete analysis of the lifecycle of all products containing the chosen materials. This modeling is being undertaken for different polymers, with an increased level of detail compared to existing studies, and targets both macro- and microplastics. This allows us to compare in a complete picture the different emission sources of plastic to the environment, identify the polymers emitted, and pinpoint possible points of action. The model focuses on emissions to water and soil environments without including fate processes such as fragmentation of macro- to microplastics. The modeling is based on probabilistic material flow analysis (PMFA) ${ }^{37}$ which allows us to account for the various uncertainties associated with the data sources. Moreover, by considering the whole life-cycle, all emissions may easily be compared to one another and no double accounting occurs. The modeling was done separately for seven of the most highly used thermoplastics. Switzerland was used as the geographic region due to the high availability of data.

\section{METHOD}

Algorithm. Material Flow Analysis (MFA) is an established method for analyzing the flows of materials through the anthroposphere in a systematic fashion. ${ }^{38,39}$ The probabilistic MFA (PMFA) method used in this work builds upon MFA by including a systematic uncertainty analysis and propagation using Monte Carlo simulations. ${ }^{37}$ This method has already been used for modeling the flows of polymers through the anthroposphere $e^{40}$ as well as several other materials. ${ }^{41-43}$ The basic principle of the model relies on two mathematical objects. The first object is a transfer coefficient (TC) matrix, which describes all the flows from one process to another. The second object is an input vector containing all the external inputs to the defined system. The matrix and vector constitute a system of linear equations, which is solved using matrix inversion. This matrix equation is solved $10^{5}$ times in a Monte Carlo setup, where every element is randomly taken from predefined probability distributions depending on data availability and quality. ${ }^{44,45}$ A schematic description of the method is given in the Supporting Information (SI) (Figure S1), and more details are available in the original publications. $^{37,40}$ For simplicity, most of the results will be presented as the mean and standard deviation of the distributions where the mean is rounded to the second significant digit of the standard deviation. ${ }^{46}$

Materials. The polymers chosen for this analysis are identical to the ones for which the flows within the anthroposphere were modeled in a previous study: ${ }^{40}$ lowdensity polyethylene (LDPE), high-density polyethylene (HDPE), polypropylene (PP), polystyrene (PS), expanded polystyrene (EPS), polyvinyl chloride (PVC), and polyethylene terephthalate (PET). These polymers were chosen on the basis of their popularity of use ${ }^{47}$ and the frequency at which they were reported in freshwaters. ${ }^{48,49}$ No additives are included in the masses reported. More details on the material definition are available in the first study. ${ }^{40}$

Flows Considered. The basis for assessing the flows of the polymers to the environment is the modeled life-cycle of the polymers within the anthroposphere. ${ }^{40}$ Some adjustments to the life-cycle description were necessary compared to the previous study to permit the modeling of emission flows. First of all, additional product categories were included to the 35 already defined in the previous study: wet wipes, sanitary pads, panty liners, tampons, tampon applicators, cotton swabs, disposable cutlery, straws, and shotgun cartridges. Second, a distinction between preconsumer waste generated by textile or plastic industries was made in order to model the emissions of pellets more accurately (Figure S16).

Building on the description of the life-cycle, emission flows were included describing the initial emission and the pathways followed until the final release into the environment (Figures S17-21 and Figure S11). Emissions of macroplastic and MP are tracked individually by creating separate compartments for both sizes of plastic in our system. This permits to account for the different processes responsible for the MP release to freshwater and soils. MP emissions occur for both MP that are designed as particles for their use, for example, preproduction pellets and MP in personal care and cosmetic products (PCCP), and for MP generated from the wear of products, for instance, fibers shed from textiles (SI chapter 4). MP can also originate from the abiotic or biotic degradation of macroplastics. In order to account for all types of sources, emission flows of both MP and macroplastics are considered. No fate processes are implemented in water and soil environments. A simple air deposition model is nevertheless implemented since particles do not stay in the air for longer time periods. The emissions of MP and macroplastics will be presented separately throughout this study. MP include all particles smaller than 5 $\mathrm{mm}$, with no strict lower size threshold since the different data underlying the model may have varying lower thresholds, and macroplastics include all pieces larger than $5 \mathrm{~mm}$.

A total of 168 flows were used to model the life-cycles of the polymers in Switzerland for the year 2014, mostly on the basis of the original study. ${ }^{40}$ They represent the flows of plastic through production, manufacturing, use, and end-of-life. In addition, 234 flows were built to model the emission pathways starting from the individual processes in the life-cycle. For both $\mathrm{MP}$ and macroplastic emissions, the emission pathways can be either direct or more intricate, by flowing through several technical compartments before reaching the environment. Both soil and freshwater environments are modeled as final environmental compartments, for which the emissions as MP and macroplastics are separately recorded. Further distinctions between residential soil, natural soil, agricultural soil, road sides, and subsurface soil are made. The definitions of residential, natural, and agricultural soils follow the classification of surface use in Switzerland. ${ }^{50}$ Road sides are defined as the immediate surrounding of highways and smaller roads. The subsurface soil compartment was defined for the release of MP due to sewer exfiltration and the MP lost from geotextiles in use. Emissions from industrial activities are released to residential soil or road sides depending on the emission process; plastics and textiles from agricultural origin are emitted into agricultural soil. MP in outdoor air was redistributed to soil or water environments using the land use as a coarse deposition model. 


\section{PP emissions in Switzerland}

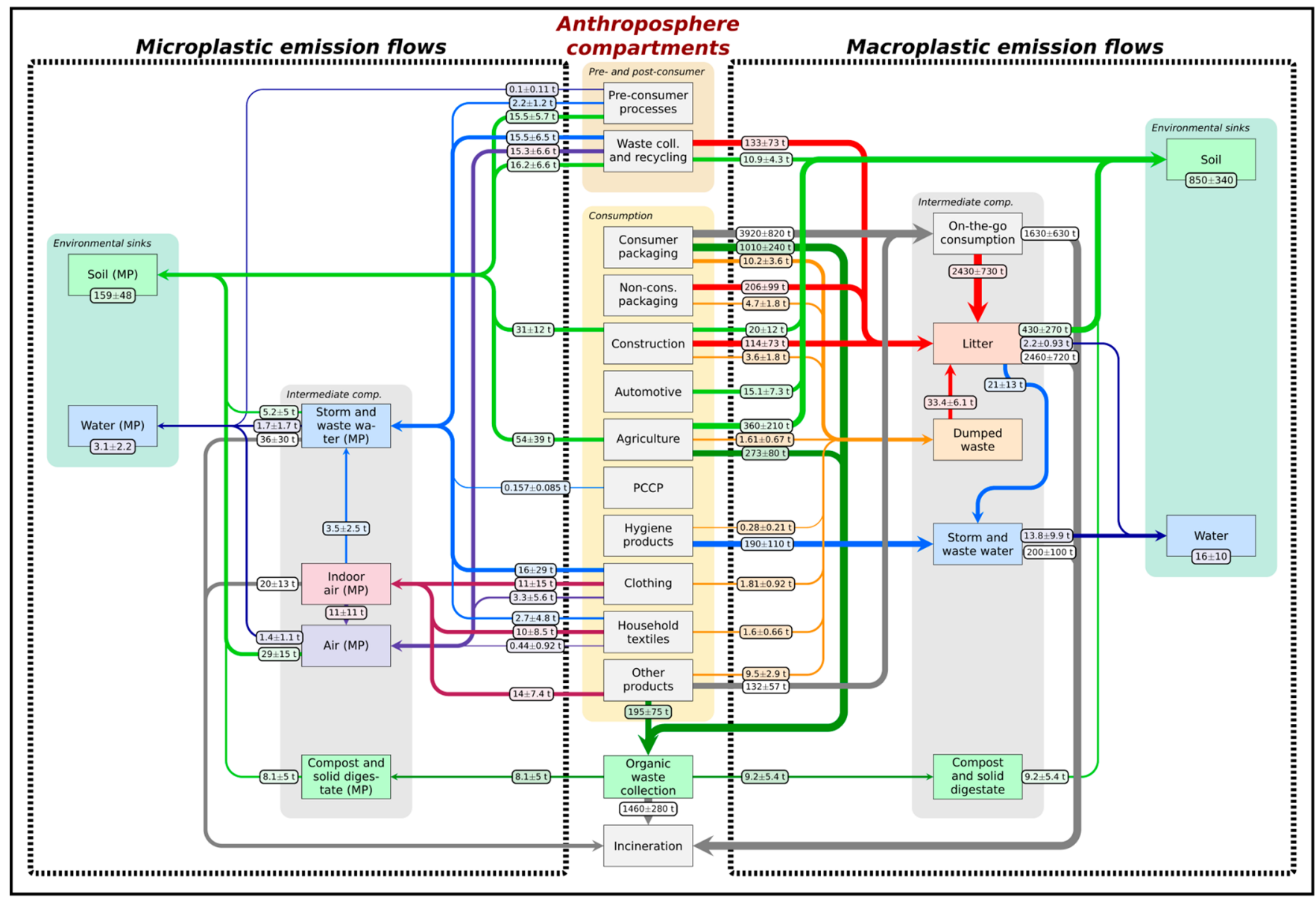

Figure 1. Aggregated emissions flows for PP in tonnes per year in Switzerland for macro- and microplastic in 2014. The aggregated flow distributions are represented after being rounded with their mean \pm standard deviation. The life-cycle processes are aggregated for visualization purposes. The life-cycle flows (not shown) are calculated based on the existing life-cycle model ${ }^{40}$ and generate the input into the aggregated compartments shown in the middle of the figure. The exact flow values for the individual compartments can be found in the table document of the SI. Equivalent flowcharts are available for the remaining polymers in Figures S5-S10. The color of the flows is representative of the receiving compartment, and the width of the flows qualitatively represents its magnitude. Abbreviations: waste collection (waste coll.), nonconsumer packaging (noncons. packaging), personal care and cosmetic product (PCCP).

Many parameters involved in the modeling of the emissions are identical for the seven polymers since the release mostly depends on the processes. The largest differences in parameters among the seven polymers are found in the lifecycles. ${ }^{40}$ A short description of the release pathways considered is presented in the following subsections and in Table S2. A complete description of the literature and data used for the modeling of the release flows is presented in the SI.

Emissions of MP Due to Wear Processes. Most of the products in use undergo wear processes, which are implemented in varying levels of detail depending on the literature available. All textile applications are subject to wear in different proportions. Emissions of MP fibers (MPF) from clothing and household textiles by washing, drying, and wearing are included. These estimates are based on the amounts of MPF released during one cycle of washing, ${ }^{51-55}$ drying, ${ }^{54}$ or wearing, ${ }^{56-58}$ the number of cycles during the whole lifetime of the products, and other parameters which were required for the implementation of the original data. The technical textiles are subject to an assumed standard shedding rate. ${ }^{59}$ The whole description for these and other emissions is available in the SI.

Intentionally Mismanaged Waste. Four distinct processes are modeled for the mismanaging of waste: littering, dumping, flushing, and contamination of organic waste. A short description of the approach is given in this section. For more details, refer to the SI.

Littering. Plastic products which are used away from home may be littered instead of being discarded in bins. ${ }^{60}$ In order to model this flow, several intermediate steps were introduced. Since only the products which are used away from home may be subject to this process, the consumption of products on-thego was estimated. In a second step, a distinction was made between products used in residential or natural areas or in the car. Once the consumption of plastic in these three areas is known, a location dependent littering probability is applied. The nonlittered portion is collected with mixed waste. The final step is the modeling of the sweeping of the litter. A fraction of the litter that is collected flows to mixed waste and the rest flows to soil, surface water, and stormwater. The products which may be subject to littering are consumer films, 


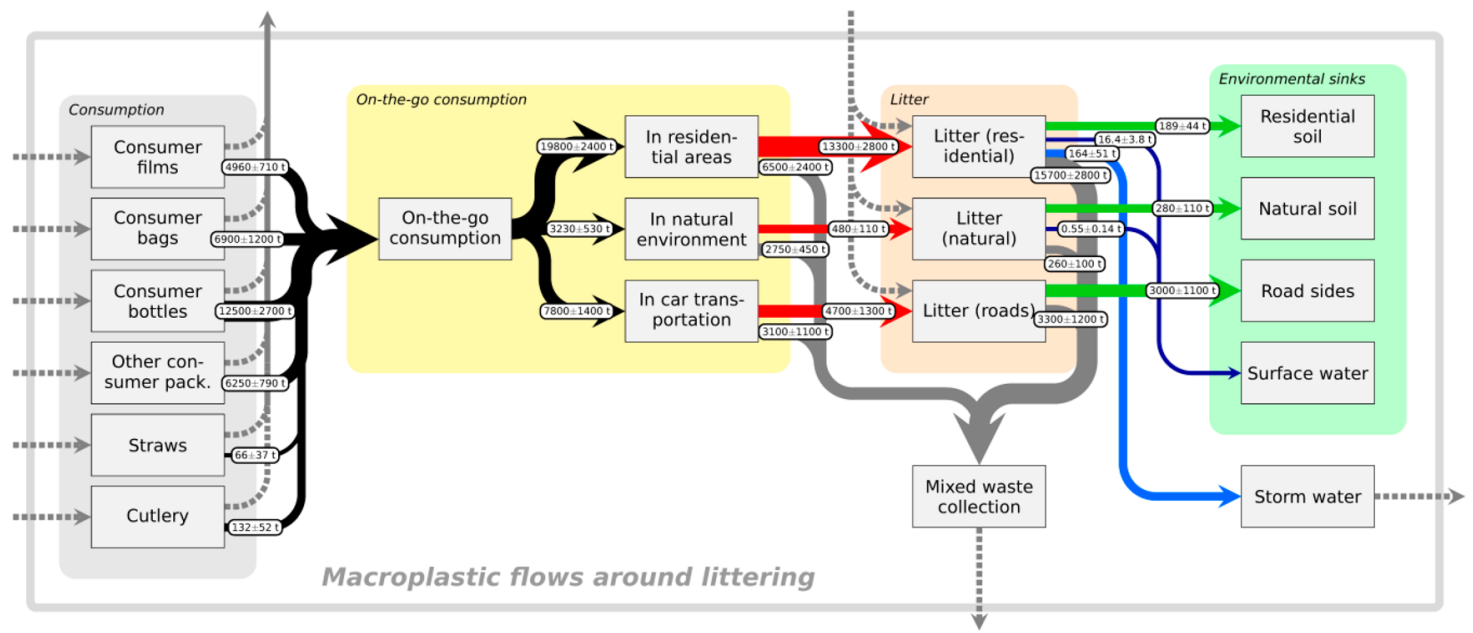

Figure 2. Detailed pathways for all flows connected to littering in Switzerland in tonnes per year, summed over all polymers. The color of the flows is representative of the receiving compartment. Dashed flows represent existing flows for which the data is not represented. The flow distributions are represented after being rounded with their mean \pm standard deviation.

bags and bottles, other consumer packaging, cutlery, and straws.

Dumping. Mismanaged waste also arises in a more premeditated manner than littering, with all the waste that is deliberately dumped outdoors. ${ }^{61}$ This process is not limited to consumer products used on-the-go and occurs for any used goods. This process is implemented for all product categories in the model except cars and mobility textiles. The litter arising through this process is redistributed to litter in residential or natural areas or road sides and then follows the same pathways as litter arising through littering.

Flushing. Sanitary waste is often flushed down the toilet instead of being discarded in the waste bin. ${ }^{62,63} \mathrm{~A}$ flushing probability is attributed to wet wipes, sanitary pads, panty liners, tampons, tampon applicators, and cotton swabs, which are then collected along with wastewater.

Contamination of Organic Waste. Various plastic products and types are found in collected organic waste. ${ }^{64-66}$ The following products may be collected inadvertently with organic waste: consumer films, consumer bags, consumer bottles, other consumer packaging, agricultural packaging films, agricultural bottles, agricultural pipes and films, other agricultural plastics, agrotextiles, household plastic, straws, and cutlery. A certain fraction of this plastic is removed during the processing of the organic waste, and the rest is distributed to agricultural and residential soil. The processing of the organic waste also causes some of the plastic to be fragmented into MP.

Unintentionally Mismanaged Waste. Some of the products found in the environment, such as plastic films from construction or industry, may be lost inadvertently due to weather or during transportation. This release is separate from plastic that is dumped or littered. Such a release is modeled for nonconsumer packaging (nonconsumer bags, nonconsumer films, other nonconsumer packaging), construction plastics (construction packaging films, pipes, insulation, coverings, profiles, lining), agricultural plastics (agricultural packaging films, agricultural packaging bottles), and automotive plastics. This litter then follows the same steps as littered waste before it is ultimately considered to have been released to the environment.

\section{RESULTS}

Emission Pathways. An aggregated overview of the emission flows is presented for PP in Figure 1 for MP and macroplastics, simultaneously, and for the six remaining polymers in Figures S5-S10. Seven hot spots for plastic release in Switzerland are as follows:

1 On-the-go consumption: for PET, HDPE, PP, LDPE, PS, and PVC

2 Postconsumer processes: for PVC, HDPE, EPS, PP, and PS

3 Use of plastic in agriculture: for LDPE and PP

4 Construction and demolition sites: for PVC, HDPE, EPS, and PS

5 Flushing of hygiene products: for HDPE, PET, and PP

6 Collection with organic waste: for PP, HDPE, LDPE, PET, and PS

7 Textiles: for PET and PP

LDPE is typically used for producing films and is largely used in packaging, construction, and agriculture. The largest emissions originate from these sectors, with consumer packaging leading by a large margin via littering with $1380 \pm$ $450 \mathrm{t}$ (Figure S5). From there, most of the emitted plastic is swept again by the authorities. A large portion, nonetheless, reaches the environment, mostly on soils. Large amounts of LDPE are also collected along with organic waste: $880 \pm 240 \mathrm{t}$ from consumer packaging and $400 \pm 170$ t from agriculture, where the vast majority is sorted out again. HDPE has a very broad range of applications which results in many different kinds of emissions (Figure S6). The largest initial release from products is found for consumer packaging litter $(3500 \pm 1100$ $\mathrm{t})$, construction $(250 \pm 130 \mathrm{t})$, and hygiene products $(210 \pm$ $180 \mathrm{t}$ ). PP also has a very large range of possible applications and therefore many types of emissions (Figure 1). Littering of consumer packaging again has the first position for the initial emission with $2430 \pm 730 \mathrm{t}$ littered, followed by items discarded in organic waste and flushed hygiene products. Large amounts of litter also arise from construction $(114 \pm 73 \mathrm{t})$ and agricultural activities $(360 \pm 210 \mathrm{t}$ to soil and $273 \pm 80 \mathrm{t}$ to organic waste collection). PS is mostly used in packaging, so littering plays a very important role in its release with a total of $760 \pm 230 \mathrm{t}$ littered (Figure S7). Large amounts of PS are also 
Microplastic emissions to soil

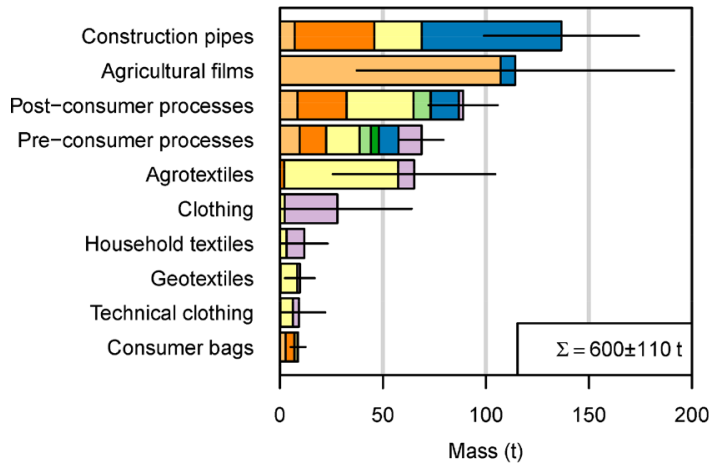

Microplastic emissions to water

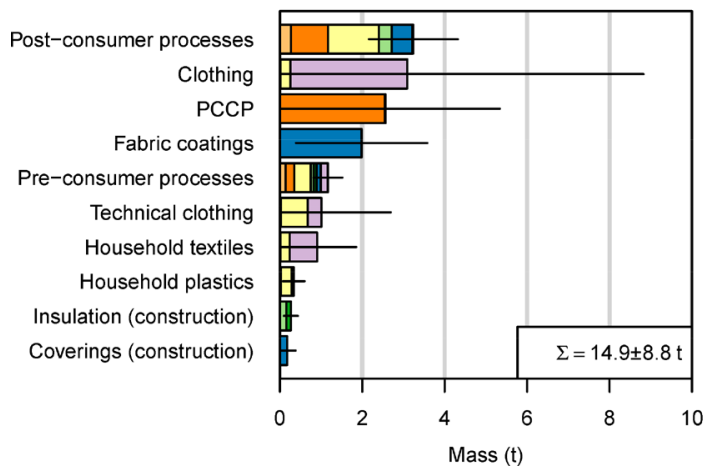

Macroplastic emissions to soil

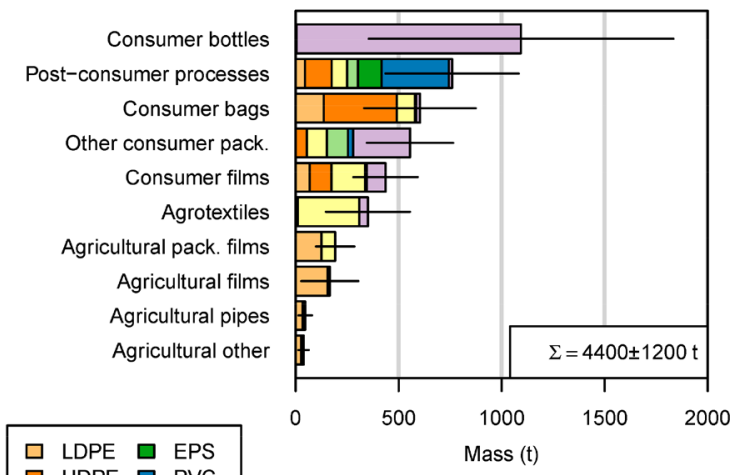

Macroplastic emissions to water

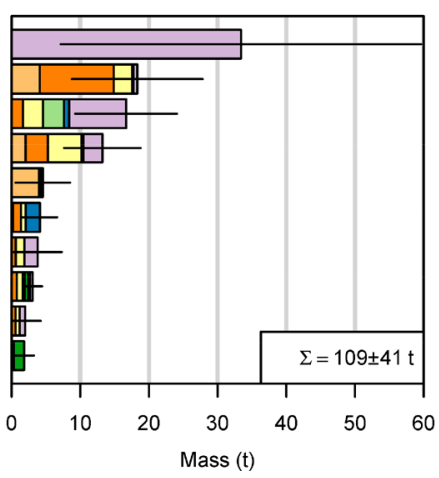

Figure 3. Macroplastic and MP emissions to soil and water in tonnes per year for Switzerland and their material composition. Only the ten largest contributions are shown. The contributions are shown by type of process, either product categories or pre- and postconsumer processes. The total release is shown in the lower right corner as mean \pm standard deviation, rounded to two significant digits of the standard deviation.

released from nonconsumer activities related to packaging, construction, and waste management. EPS and PVC are mostly used in construction, which is again reflected in the predicted emissions (Figures S8-S9). $240 \pm 130 \mathrm{t}$ EPS and $690 \pm 260 \mathrm{t}$ PVC litter arises from construction activities of which a large fraction is swept. Large emissions of EPS and PVC are also caused by the collection of construction waste. PVC is also subject to littering to a large extent with $235 \pm 88 \mathrm{t}$ littered every year. Lastly, for PET, there is a very clear domination of release through littering with $10100 \pm 2800 \mathrm{t}$ before sweeping (Figure S10). Large amounts of PET MPF are also released from textile applications, even though the amount initially released from textiles is 2 orders of magnitude lower than the amount of PET littered.

For all mentioned polymers, one of the most preeminent emissions is almost always caused by littering. More details about the flows during littering are shown in Figure 2. The only parameters that are polymer dependent for littering are the fractions of the packaging product categories used on-thego, which were available for the seven materials. ${ }^{67}$ Between $5 \%$ and $35 \%$ of the used consumer packaging applications are consumed away from home depending on the polymer and the product. Consumer bottles, in particular, of which $35 \%$ are used away from home present a higher potential for littering. According to our estimates, $25 \%$ of this packaging used away from home is used in transportation, $10 \%$ in natural environments, and the rest in residential areas. A total of $22900 \pm 3300 t$ of litter of all seven polymers are generated along road sides in residential and natural areas according to our model. The largest amount of litter generated arises for
PET because of the high consumption of PET bottles and their high on-the-go consumption. As mentioned earlier, most of the litter arises in residential areas, followed by road sides and natural environments. Because of the different sweeping efficiencies considered, most litter remaining after sweeping is found along road sides and in natural environments. Quantitative information on the differences between the materials is given in the SI.

The second most important release for most polymers is caused by mismanaged agricultural products. In total, $800 \pm$ $280 \mathrm{t}$ of the seven polymers are directly emitted to agricultural soil by burying after use. Most of this plastic consists of PP with $360 \pm 210 \mathrm{t}$ and LDPE with $340 \pm 180 \mathrm{t}$ buried, followed by $41 \pm 36$ t PET, $29 \pm 22$ t PVC, $24 \pm 12$ t HDPE, and $2.2 \pm$ $2.1 \mathrm{t}$ PS.

Other important indirect emissions flows are caused by stormwater and wastewater management (Figure S11). Every year, $600 \pm 300 \mathrm{t}$ of macroplastics and $210 \pm 150 \mathrm{t}$ of MP are emitted to wastewater (Figure S12). All of the macroplastics released to wastewater are hygiene articles that are flushed instead of being appropriately discarded. Macroplastics can only escape WWTPs through combined sewer overflows (CSOs), except for cotton swabs which may escape secondary treatment. Nevertheless, cotton swabs are among the least flushed items in terms of mass along with cleaning cloths (Figure S12). Much larger masses of wet wipes and feminine hygiene products are flushed; however, since $100 \%$ of the large macroplastic are retained in WWTPs overall, the emission of such items through the WWTP becomes negligible. The emissions caused by CSOs cause the largest emissions of these 
products with a total of $10.6 \pm 7.2$ of all polymers and products combined. Less MP enter WWTPs than macroplastics, yet the emissions to surface water are almost as important. The largest MP releases to wastewater are caused by PCCP and clothing. Smaller releases originate from postconsumer processes, technical clothing, and household textiles. The largest amounts of MP escape through CSOs at $6.2 \pm 4.7 \mathrm{t}$, and significant amounts also leave from tertiary treatment at $1.4 \pm 4.4 \mathrm{t}$. The largest emissions caused by wastewater nevertheless flow to subsurface soils through exfiltration from sewers at around 23 \pm 19 t.

An important MP release pathway to soil and surface water environments occurs through air deposition. MP including 32 $\pm 35 \mathrm{t}$ of PET, $30 \pm 15 \mathrm{t}$ of PP, $11.7 \pm 6.2 \mathrm{t}$ of HDPE, $9.3 \pm$ $4.9 \mathrm{t}$ of PVC, $8.0 \pm 3.4 \mathrm{t}$ of PS, $3.3 \pm 1.4 \mathrm{t}$ of LDPE, and 2.42 $\pm 0.60 \mathrm{t}$ of EPS are transported through outdoor air and deposit onto soil or surface water (Figure 1 and Figures S5S10). PET emissions to outdoor air are dominated by emissions from indoor air of MPF from clothing and household textiles. Around 33\% of the MP emitted to indoor air are released to outdoor air through air exchanges between the two environments in our model. The largest emissions to indoor air are caused by MPF shed from clothing and household textiles, which also contribute to the largest emissions to outdoor air after postconsumer processes. PP emissions to outdoor air are dominated by emissions from waste collection and recycling at $15.3 \pm 6.6 \mathrm{t}$, more specifically from automotive shredder residue and waste electrical and electronic plastic which are often shredded in the open. Large amounts of PP MP are also emitted to outdoor air from indoor environments at $11 \pm 11 \mathrm{t}$. Similarly, for HDPE, PS, PVC, and LDPE, MP emissions to outdoor air are primarily caused by the recycling processes of cars and electronics. For PS and EPS, emissions from construction and demolition activities are also very relevant at $3.4 \pm 2.5 \mathrm{t}$ PS and $2.42 \pm 0.60 \mathrm{t}$ EPS.

An overview of the final emissions caused by individual products is given in Figure 3, with aggregated emissions from pre- and postconsumer processes. The largest emissions to soil occur for consumer packaging as macroplastics through littering and from waste management and recycling. Large amounts of macroplastics are also released by the burying of agricultural goods that reach their end-of-life. The next largest emission to soil is caused by the cutting of construction pipes and agricultural film fragmentation during use, both of which generate MP. The total macroplastic emissions to soil sum up to $4400 \pm 1200 \mathrm{t}$ and the total MP emissions to $600 \pm 110 \mathrm{t}$. Similarly, more macroplastics are emitted to freshwater than $\mathrm{MP}$, at $109 \pm 41 \mathrm{t}$ of macroplastic and $14.9 \pm 8.8 \mathrm{t}$ of MP. Consumer packaging littered is the leading emission of macroplastics also for surface waters. Smaller yet relevant emissions are caused by MP released from recycling processes. Emissions of macroplastics by industrial activities, nonconsumer packaging, and construction sites are also relevant. Hygiene articles flushed and collected with wastewater also figure in the largest emissions of macroplastics to surface waters. Other MP emissions to surface water are caused primarily by clothing and PCCP, followed by fabric coatings, preconsumer processes, and household textiles.

Receiving Environmental Compartments. The distribution of the release among environmental compartments varies as a function of the polymer and the type of emission (Figure 4). The main reason for this variation is due to the different applications of each polymer. LDPE and PP MP are

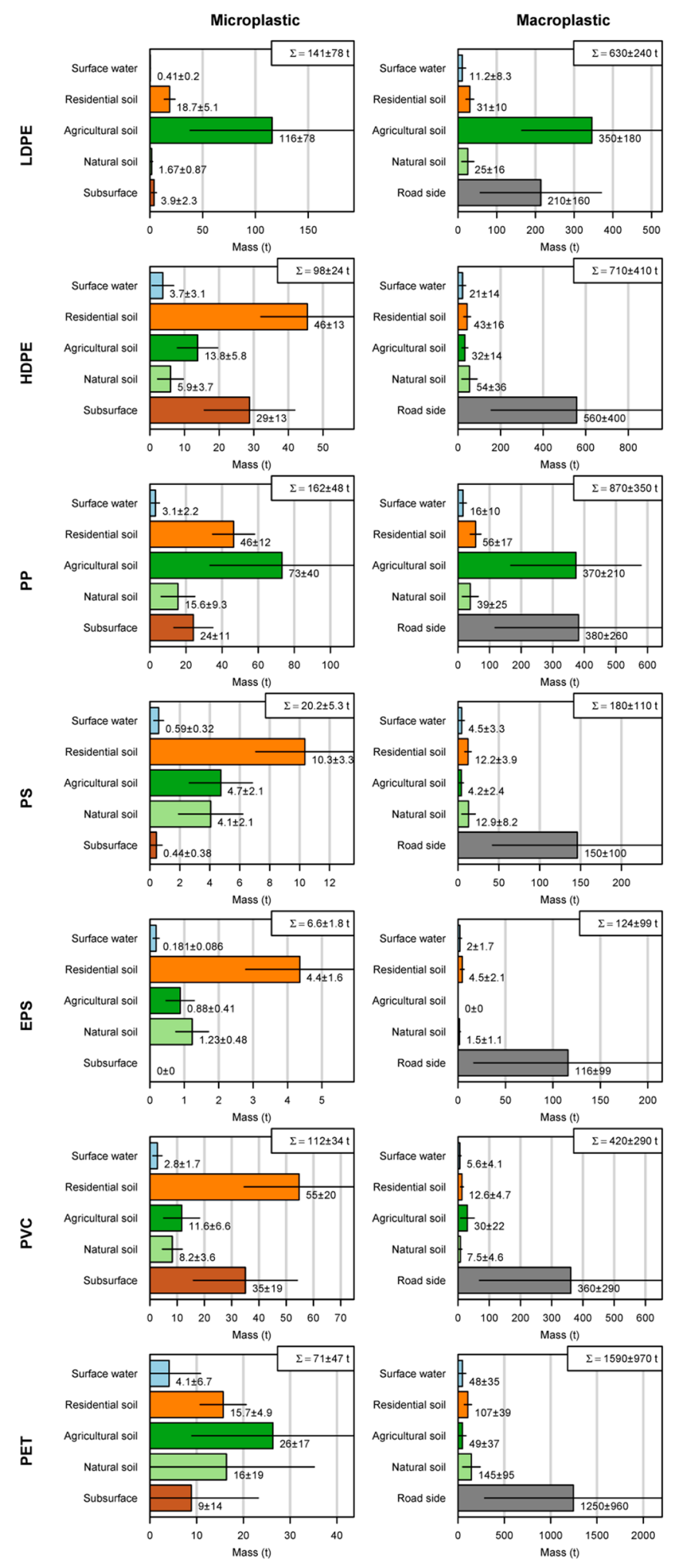

Figure 4. Comparison of the total emissions by polymer, type of emission (MP or macroplastic), and final compartment in tonnes per year for Switzerland. The total amount of polymer released as MP or macroplastic is displayed in the upper right corner as mean \pm standard deviation, rounded to two significant digits of the standard deviation.

mostly emitted to agricultural soil due to the use of LDPE films and PP agrotextiles in agriculture. Around $80 \%$ of LDPE MP emissions flow to agricultural soil, and $45 \%$ of PP MP. The 


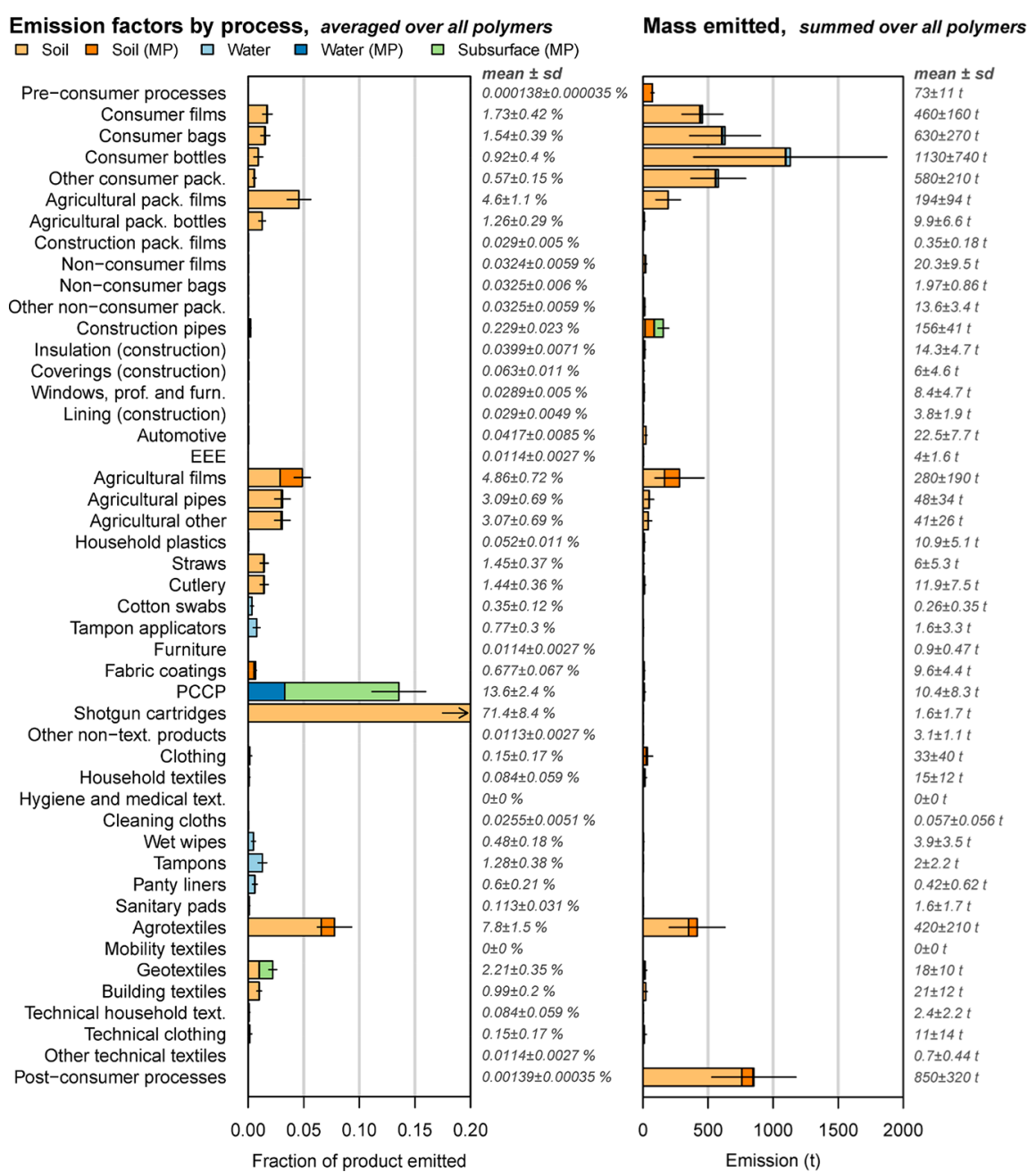

Figure 5. Emission factors (left) and total mass released in tonnes per year (right) by product and receiving environmental compartment for Switzerland. The emission factors are averaged over the seven different polymers and the emission masses are summed over the seven polymers. For "pre-consumer processes" and "post-consumer processes", a weighted average over the emissions from the subprocesses was calculated, using the mass in the subprocesses as weight. All displayed numbers are shown as mean \pm standard deviation, rounded to two significant digits of the standard deviation. Abbreviations: electrical and electronic equipment (EEE), personal care and cosmetic products (PCCP), textile (text.).

emissions of LDPE MP to other compartments are much lower in comparison. Around $30 \%$ of the PP MP is emitted to residential soil and only around $10 \%$ to natural soil. HDPE MP is mostly emitted to residential soil with $50 \%$ of the emissions because of nonconsumer activities, followed by subsurface soil with around $30 \%$ because of the assumed wear of HDPE pipes in use. Around half of PS MP is emitted to residential soil because of nonconsumer activities. Around two-thirds of EPS and half of PVC MP emissions land in residential soil, because of preconsumer processes in the case of EPS and construction activities for PVC. A large amount of PVC MP also ends in subsurface soil because of the wear of pipes during use. PET MP is mostly emitted to agricultural soil (around 36\%) through air deposition, wear of agrotextiles, and compost and digestate application onto land. With all polymers combined, MP is mainly emitted to agricultural soil, followed by residential soil and subsurface soil (Figure S13).

Macroplastics of all polymers are found mostly on road sides (Figure 4) because of littered consumer packaging and lost construction and demolition waste. An exception to this exists for LDPE and PP for which around half of the macroplastics are emitted to agricultural soil, caused by burying of agricultural products. With all polymers combined, road side pollution constitutes $67 \%$ of all the macroplastic emissions (Figure S13). Agricultural and residential soils then contribute to around $24 \%$ of the emissions together. Only $6.3 \%$ of all the macroplastics emitted flows to natural soil, and $2.4 \%$ flows to surface water. It thus appears that for both MP and macroplastic emissions, most of the burdens is initially emitted into soils.

Emission Factors. According to our model, $0.59 \pm 0.16 \%$ of the mass of polymer consumed in Switzerland is released to the environment when emissions occurring outside of the consumption phase are neglected. This overall emission factors are different for the seven polymers: $0.64 \pm 0.23 \%$ of LDPE, $0.53 \pm 0.28 \%$ of HDPE, $0.57 \pm 0.19 \%$ of PP, $0.24 \pm 0.14 \%$ of PS, $0.037 \pm 0.012 \%$ of EPS, $0.177 \pm 0.047 \%$ of PVC, and 1.25 $\pm 0.73 \%$ of PET.

In Figure 5, the emission factors and the mass of the products emitted are compared for all product categories considered in the model and pre- and postconsumer processes. Consumer packaging is responsible for the largest macroplastic emissions to soil, followed by postconsumer processes, agricultural applications, construction pipes, and preconsumer processes. The remaining emissions are much smaller compared to those of these products. The largest emission 
factors are found for shotgun cartridges with $71.4 \pm 8.4 \%$ of the cartridges consumed being released directly into the environment during use. The second largest emission factor is found for PCCPs with $13.6 \pm 2.4 \%$ of the total mass consumed being released of which a large amount is released to subsurface soil through exfiltration from sewers. Agricultural products also have large emission factors, ranging from $7.8 \pm$ $1.5 \%$ for agrotextiles to $1.26 \pm 0.29 \%$ for bottles. Other products with large emission factors are consumer packaging, hygiene products, straws, and cutlery.

\section{DISCUSSION}

Overall Release of Polymers to the Environment. Several assessments of macro- and microplastic emissions have already been published. Nevertheless, the results from different studies cannot be compared easily because of the differences in scope. More often than not, the largest emission flows in previous assessments originate from tire wear ${ }^{25,26,29,30}$ which consist of other polymers than those considered here. The materials included in the present study were chosen according to the prevalence of the polymer types measured in freshwater. ${ }^{40}$ This issue highlights the importance of moving away from references to "plastics" instead of specific polymers.

For Europe, it was previously assumed that approximately $6-10 \%$ of the plastic produced was emitted to the oceans. ${ }^{27}$ On a global scale, estimates of the amount of mismanaged waste reaching the oceans was estimated to be $2-5 \% .{ }^{33}$ The plastic litter input into the oceans from rivers was estimated based on the amount of mismanaged waste ${ }^{34}$ by countries around the world. Globally, 32\% of all the plastic waste generated was modeled as being mismanaged and after calibration, with measurements in rivers, it was estimated that $1-2 \%$ of the plastic waste generated globally reached the oceans. ${ }^{34}$ Such broad estimates are good first estimates, yet they need to be improved by more accurate and specific numbers. Our results clearly show that using a generic release estimate for all existing plastic products is not feasible, as the life-cycle of the different applications is very different. Moreover, large regional differences may be expected, depending on the regional waste management practices, and global emission rates will not be representative of the emissions of any one country.

A comparison by emission type can be done for the most important flows in this model, starting with the largest emission source of plastic to the environment according to the present study: littering. Previous estimates of quantities of plastic released due to littering use littering rates of around $2 \%{ }^{33}$ This value combines the different parameters modeled in our study: on-the-go consumption, littering probability, and sweeping efficiency. According to our results, $1.2 \pm 0.5 \%$ of the products consumed on-the-go is released to the environment due to littering. However, the previous studies applied the littering rate to all plastic applications which led to a large overestimation of the amount of plastic pollution caused by littering, since only products used on-the-go may be littered.

Little information can be found on other emission flows in literature. Emissions from agriculture and construction which may both be very relevant are omitted from existing plastic emission assessments.

Per Capita Polymer Emissions. In order to allow a comparison with other published plastic release estimates, we converted the released masses into per capita flows using a population of 8.19 million $^{68}$ in Switzerland for 2014. In total,
$94 \pm 34 \mathrm{~g} /$ cap of LDPE enter the Swiss environment per year, aggregated over all environmental compartments and considering both MP and macroplastic. The corresponding numbers for the other polymers are $98 \pm 50 \mathrm{~g} / \mathrm{cap}$ of HDPE, $126 \pm 43$ $\mathrm{g} /$ cap of PP, $24 \pm 13 \mathrm{~g} /$ cap of PS, $16 \pm 12 \mathrm{~g} /$ cap of EPS, $65 \pm$ $36 \mathrm{~g} /$ cap of PVC, and $200 \pm 120 \mathrm{~g} /$ cap of PET. With all seven polymers combined, $630 \pm 150 \mathrm{~g} / \mathrm{cap}$ of plastic enters the environment per year. Modeled emissions to soil are much higher than emissions to freshwater for all polymers: $610 \pm$ $150 \mathrm{~g} / \mathrm{cap}$ are emitted to soil and $15.1 \pm 5.1 \mathrm{~g} / \mathrm{cap}$ are emitted to water; $1.8 \pm 1.1 \mathrm{~g} / \mathrm{cap}$ enters waters as MP, and $13.3 \pm 4.9$ $\mathrm{g} /$ cap enters water as macroplastics. For soils, the corresponding flows are $73 \pm 14 \mathrm{~g} / \mathrm{cap}$ as MP and $540 \pm 140 \mathrm{~g} / \mathrm{cap}$ as macroplastics. The difference in MP and macroplastic emissions is primarily due to the prevalence of emissions from consumer packaging for most polymers. We predict that soils receive 40 times more plastic (both macro- and microplastics) than waters. This means that much more focus should be placed on this compartment, both in relation to future research as well as for regulators.

Previous estimates of plastic emissions range from $8 \mathrm{~g} / \mathrm{cap}^{69}$ for MP added intentionally in products to $5400 \mathrm{~g} / \mathrm{cap}^{28}$ for many types of emissions. When we compare all of these studies together, our estimates are much smaller, especially for MP. It should however be noted that depending on the study, tire wear represents between $26^{27}$ to $79 \%$ of the total MP emissions. Publishing release estimates while distinguishing between materials involved will therefore be central to the assessment of the impacts of synthetic microparticles. Tire wear particles may be linked to entirely different environmental issues and risks ${ }^{70}$ than particles consisting of nonrubber plastic. $^{23,24}$ Paints and coatings also represent large portions of the previously published estimates. When all the emission sources which are not included in the present study are removed from previously published estimates, one obtains emissions of $129,{ }^{25} 3.6-95,{ }^{26} 4.7-32.25,{ }^{31}$ or $108 \mathrm{~g} / \mathrm{cap}^{30}$ for MP reaching aquatic environments or $858 \mathrm{~g} / \mathrm{cap}^{28}$ emitted without specification of the receiving compartments. Our estimate of MP reaching surface waters is $1.8 \pm 1.1 \mathrm{~g} / \mathrm{cap}$ lower than all these estimates. This highlights the importance of moving away from generic release estimates to more product- and polymer-specific assessments and also shows that using global values will not capture the release flows in an industrialized country with an efficient waste management system.

Comparison with Measured Emissions. Although many measurements of MP in freshwater exist, it is difficult to use them for a comparison with our model results as we predict releases and not environmental exposure. Fate processes occurring after the emissions are not part of the model, which is very important in order to predict actual concentrations. The macroplastics and MP will be affected by sedimentation, runoff, fluvial transport, fragmentation, and degradation. The presented data may serve as the basis for the creation of such fate models ${ }^{71}$ but cannot predict environmental concentrations.

The order of magnitude of the modeled emissions can be put into perspective using the estimated amount of plastic litter on Swiss lakes and river shores obtained from the Swiss Litter Report by sampling of litter. ${ }^{72}$ According to this study, around $276 \mathrm{t} /$ year of plastic can be found along shores in Switzerland, assuming that the litter collections are independent for an interval of one month. ${ }^{73}$ Our model estimates $109 \pm 41 \mathrm{t} /$ year 
of macroplastics released to water, which is of the same order of magnitude as the value obtained through upscaling of the data from the Swiss Litter Report to Switzerland.

For a few of the processes in our model, a comparison with measured values can be made. The high amount of sanitary items in surface waters predicted by our model is correlated to the prevalence of such products in litter inventories from field studies. According to the Swiss Litter Report, ${ }^{72}$ one cotton swab is found on every $100 \mathrm{~m}^{2}$ of shores in Switzerland per month. A rough estimation of the number of cotton bud sticks on river and lake sides can be made by using the length of the hydrographic network of Switzerland and the length of the shorelines of the lakes. ${ }^{74}$ Assuming a shore is $1-5 \mathrm{~m}$ broad, one cotton swab may be found every $20-100 \mathrm{~m}$ of the shore every month, resulting in 2.9 million-4 million cotton swabs per year. A total of 2.3 million cotton swabs are emitted per year to surface waters in Switzerland according to our model, using the mass of a single cotton swab (see SI), which lies on the lower range of the estimate based on the Swiss Litter Report.

A comparison can also be made with the total amount of sanitary textiles collected on screenings in four different WWTPs in France, which were reported to range from 400 to $1700 \mathrm{~g} / \mathrm{cap} /$ year. $^{75}$ The present model predicts that a total of $73 \pm 37 \mathrm{~g} / \mathrm{cap} /$ year of macroplastics enter the WWTPs in Switzerland. This value encompasses only the seven polymers considered in the model which make up $6-73 \%$ of the composition of the sanitary product (see SI). This comparison tends to show that the amount of sanitary items flushed is not overestimated.

Emissions of MP through wastewater can be compared using measurements of MP burdens in wastewater in 28 WWTPs in the canton of Zurich. ${ }^{76}$ From these measurements, it was estimated that $600 \mathrm{~g} /$ day of MP enter surface waters from the Canton of Zurich alone. When we scale up these values to Switzerland, we obtain a resulting value of $1.2 \mathrm{t}$ of MP. ${ }^{77} \mathrm{~A}$ total release of $1.5 \pm 4.6 \mathrm{t}$ MP through WWTPs from the seven polymers considered was estimated within this study, which is in good agreement with the estimate obtained from the measurements.

The predicted emissions to air can also be put into perspective with other approaches. According to our model, $98 \pm 47 \mathrm{t}$ of $\mathrm{MP}$ are emitted to outdoor air per year, originating to a large extent from postconsumer processes due to dust generated from shredding in recycling sites and from textile wear. This value can be compared to the reported atmospheric deposition of MPF in Paris. ${ }^{78}$ Between 3 and $10 \mathrm{t}$ of fibers were estimated to deposit on the Parisian agglomeration every year of which around 29\% were synthetic. $^{78}$ By scaling to the area and the Swiss population, we can estimate that $0.57-1.97 \mathrm{t} /$ year are deposited on soil and water environments. Two key uncertainties are worth mentioning: the shedding rate which can be applied to various types of textiles, and the air exchange rate between indoor and outdoor air. The estimated dust mass that is deposited in households in Switzerland can be compared to dust deposition rates as known from literature ${ }^{79-81}$ which are in the range of $1.1-2.4 \mathrm{~g} / \mathrm{m}^{2} /$ year. The useful floor space in Switzerland is estimated to be 0.62 billion $\mathrm{m}^{2}$, 82 resulting in approximately $680-1500 \mathrm{t} / \mathrm{y}$ of indoor dust deposited in Switzerland. The synthetic fiber content in dust was reported to be $1-5 \%{ }^{83}$ by volume in a household or $1.5 \%{ }^{84}$ by mass in an office. Consequently, 6.8-34t of synthetic fibers would be a possible range of the amount of synthetic fibers deposited in indoor environments in Switzerland every year compared to a model prediction of $109 \pm 69 \mathrm{t}$ MP. The discrepancy of the two estimates by a factor of 3-16 may suggest that our evaluation of the fiber shedding processes may be overestimated. However, it is smaller than the discrepancy in the estimates of MP in outdoor air presented earlier. Very large uncertainties are attached to the dust generation rate and the useful floor space to which the dust generation rate is applied. The shedding rate of MPF used in the presented model may depend on parameters such as the activity performed, the type of garment, the cleanliness of the clothes, and the ambient relative humidity. ${ }^{58}$ Because of the lack of literature on emissions of fibers caused by wear and drying, their description was simplified. More research on the mechanics underlying these shedding processes as well as the various uses of textiles would clarify the importance of MPF shed indoors for the MP present in outdoor air.

Assessment of Model Uncertainty. The PMFA method enables us to consider the uncertainty associated with each parameter used in the model. This uncertainty is then directly reflected in the final results which may have greatly varying relative uncertainties (Figure S15). These differences in confidence in the predicted results can easily be explained by considering the distribution of the parameters influencing it. The relative uncertainty of the mass contained in compartments ranges from 7 to $538 \%$, with a median relative uncertainty of $39 \%$. Low relative uncertainties are found for results depending on well-known parameters, and higher uncertainties are given for less confident predictions. In this manner, no false confidence in the results is given from the model. For example, a very high relative uncertainty is attributed to the amount of MP found in tertiary treatment in WWTPs, with a value of around $300 \%$ for most polymers and as high as $538 \%$ for PET. For all polymers, a strong influence on this final relative uncertainty comes from the high variability in removal efficiencies for the different treatment stages in the WWTP (see additional table document in the SI). The removal efficiencies during primary treatment range from $50 \%{ }^{85}$ to $98 \%{ }^{86}$ and during secondary treatment from $7 \%{ }^{86}$ to $81 \%{ }^{76}$ In the case of PET, there is an important additional uncertainty coming from the release of fibers from textiles (Figure S22) where data scarcity and variability leads these parameters to have very long tails in their distributions and a high skewness. This leads the calculated standard deviation to reach very high values. This is reflected in the high relative uncertainty for the amount of MP released from clothing at 4.8 $\pm 5.8 \mathrm{t}$ (Figure 5) and for the final amount of PET MP found in surface waters at $4.1 \pm 6.7 \mathrm{t}$ (Figure 4 ). In conclusion, while we can expect to have considerable uncertainty in a few parameters considered in the model, this uncertainty is then reflected and presented in the confidence attributed to the results.

An additional uncertainty may come from the processes considered in the model itself. To reduce this uncertainty as much as possible, a high degree of detail was chosen for the modeling. Nevertheless, specific emission flows may be missing from the inventory if the corresponding processes are not part of the system. It is noteworthy to mention that fishing products were not included in the study, since the fishing industry has a low importance in Switzerland. However, if these results were to be applied to another country, regional differences should be taken into account. Other plastic emissions may be 
expected if their origins were not included in the modeled lifecycle, but we expect this to be of low importance for Switzerland, considering the low mass contained in the process "other products".

Policy Recommendations. A comparison of the emission factors and the mass of the product emitted gives insight into the efficiency of the mitigation options. According to the total masses, consumer packaging would need to be examined first to reduce the exposure of plastic in the environment. A reduction of emission for these products would have the most impact on the total mass of plastic emitted. However, if one considers that only around $1 \%$ of the consumer packaging used causes such large emissions and that littering is a widespread phenomenon, mitigation seems more difficult. The next largest emission is found for postconsumer processes for which very small emission factors are responsible. Most of these emissions are caused by construction sites and construction waste collection. Similar to consumer packaging, mitigation might be difficult. Agricultural products also cause considerable emissions and have large emission factors, making a possible mitigation easier. For products with great emission factors, there is a large potential for improvement on an individual scale. The products with the biggest emission factors are shotgun cartridges and PCCP, yet only $0.22 \pm 0.24 \mathrm{t}$ of shotgun cartridges and $1.5 \pm 1.2 \mathrm{t}$ of PCCP reach the environment. A large fraction of the PCCP released flows to subsurface soil due to exfiltration from sewers. When these emissions are compared to the total annual emissions of 5300 $\pm 1100 \mathrm{t}$ in Switzerland, the reduction of these emissions seems less urgent than the other ones.

From our analysis of the polymer flows to the environment, we can conclude that the following initiatives would be the most effective solutions in the reduction of plastic pollution:

1 Increased attention needs to be given to MP in soils where the largest flows are occurring. There is currently more information available on MP in waters likely because of the easier analytics and the experience gained in the oceans, yet the modeling results clearly advocate for a much larger focus on soil.

2 Many of the largest emissions of macroplastics to soil and water are caused by single-use plastics (Figure 3). An action plan such as the one proposed by the European Parliament ${ }^{87}$ may improve the situation, since it is meant to cover single-use plastics, for example, takeaway packaging and sanitary products.

3 Reducing littering and/or improving sweeping may have a large impact on the total environmental burden. Large efforts have already been made in that direction, through education, campaigns, and cleaning. Even though the efficiency of the campaigns is debated, an improvement of the situation has been suggested over the last couple of years in Switzerland. ${ }^{88}$

4 Improving the waste management practices in construction and agriculture would reduce the emissions caused by these sectors, which are only second to consumer packaging. It should nevertheless be highlighted that the emission flows from agriculture are very uncertain and not specific to Switzerland due to a lack of data, and the emission flows from construction are based on local data. More research into this area should be encouraged.
5 For further improvement, many measures aiming at incremental improvement may be suggested, for example, reducing the occurrence of combined sewer overflows. The inhibition of the shedding of MP fibers from textiles caused by washing, wearing, and drying would reduce one of the largest emissions of MP in surface waters and should be looked into more in detail. Similarly, reducing the use of PCCPs would reduce the emissions of MP in surface waters. With regard to this specific product, media coverage and public attention have led companies to reduce their use of some of these polymers already. ${ }^{89}$ Legal restriction of the use of intentionally added MP in products has also been proposed. $^{90}$

\section{ASSOCIATED CONTENT}

\section{S Supporting Information}

The Supporting Information is available free of charge on the ACS Publications website at DOI: 10.1021/acs.est.9b02900.

Figures for the method and the results, detailed description of parameters and assumptions underlying the model (PDF)

Parameter table: data used for the model and associated uncertainty (XLSX)

Results table including information on the flows resulting from the calculation for each polymer: mean, $\mathrm{SD}$, and quantiles (XLSX)

\section{AUTHOR INFORMATION}

\section{Corresponding Author}

*E-mail: nowack@empa.ch.

ORCID

Bernd Nowack: 0000-0002-5676-112X

Notes

The authors declare no competing financial interest.

\section{ACKNOWLEDGMENTS}

This work was supported by the Swiss Federal Office for the Environment (BAFU).

\section{REFERENCES}

(1) Klein, S.; Worch, E.; Knepper, T. P. Occurrence and Spatial Distribution of Microplastics in River Shore Sediments of the RhineMain Area in Germany. Environ. Sci. Technol. 2015, 49 (10), 60706076.

(2) Dris, R.; Gasperi, J.; Rocher, V.; Saad, M.; Renault, N.; Tassin, B. Microplastic Contamination in an Urban Area: A Case Study in Greater Paris. Environ. Chem. 2015, 12 (5), 592-599.

(3) Imhof, H. K.; Ivleva, N. P.; Schmid, J.; Niessner, R.; Laforsch, C. Contamination of Beach Sediments of a Subalpine Lake with Microplastic Particles. Curr. Biol. 2013, 23 (19), R867-R868.

(4) Eriksen, M.; Mason, S.; Wilson, S.; Box, C.; Zellers, A.; Edwards, W.; Farley, H.; Amato, S. Microplastic Pollution in the Surface Waters of the Laurentian Great Lakes. Mar. Pollut. Bull. 2013, 77 (1-2), 177-182.

(5) Biginagwa, F. J.; Mayoma, B. S.; Shashoua, Y.; Syberg, K.; Khan, F. R. First Evidence of Microplastics in the African Great Lakes: Recovery from Lake Victoria Nile Perch and Nile Tilapia. J. Great Lakes Res. 2016, 42 (1), 146-149.

(6) Zhang, W.; Zhang, S.; Wang, J.; Wang, Y.; Mu, J.; Wang, P.; Lin, X.; Ma, D. Microplastic Pollution in the Surface Waters of the Bohai Sea, China. Environ. Pollut. 2017, 231, 541-548. 
(7) Zhang, K.; Gong, W.; Lv, J.; Xiong, X.; Wu, C. Accumulation of Floating Microplastics behind the Three Gorges Dam. Environ. Pollut. 2015, 204, 117-123.

(8) Sruthy, S.; Ramasamy, E. V. Microplastic Pollution in Vembanad Lake, Kerala, India: The First Report of Microplastics in Lake and Estuarine Sediments in India. Environ. Pollut. 2017, 222, 315-322.

(9) Dris, R.; Gasperi, J.; Rocher, V.; Tassin, B. Synthetic and NonSynthetic Anthropogenic Fibers in a River under the Impact of Paris Megacity: Sampling Methodological Aspects and Flux Estimations. Sci. Total Environ. 2018, 618, 157-164.

(10) Free, C. M.; Jensen, O. P.; Mason, S. A.; Eriksen, M.; Williamson, N. J.; Boldgiv, B. High-Levels of Microplastic Pollution in a Large, Remote, Mountain Lake. Mar. Pollut. Bull. 2014, 85 (1), 156-163.

(11) Scheurer, M.; Bigalke, M. Microplastics in Swiss Floodplain Soils. Environ. Sci. Technol. 2018, 52 (6), 3591-3598.

(12) Rillig, M. C. Microplastic in Terrestrial Ecosystems and the Soil? Environ. Sci. Technol. 2012, 46 (12), 6453-6454.

(13) Ng, E.-L.; Huerta Lwanga, E.; Eldridge, S. M.; Johnston, P.; Hu, H.-W.; Geissen, V.; Chen, D. An Overview of Microplastic and Nanoplastic Pollution in Agroecosystems. Sci. Total Environ. 2018, 627, 1377-1388.

(14) de Souza Machado, A. A.; Kloas, W.; Zarfl, C.; Hempel, S.; Rillig, M. C. Microplastics as an Emerging Threat to Terrestrial Ecosystems. Glob. Chang. Biol. 2018, 24, 1405.

(15) Nizzetto, L.; Futter, M.; Langaas, S. Are Agricultural Soils Dumps for Microplastics of Urban Origin? Environ. Sci. Technol. 2016, 50 (20), 10777-10779.

(16) Zubris, K. A. V; Richards, B. K. Synthetic Fibers as an Indicator of Land Application of Sludge. Environ. Pollut. 2005, 138 (2), 201211.

(17) Bläsing, M.; Amelung, W. Plastics in Soil: Analytical Methods and Possible Sources. Sci. Total Environ. 2018, 612, 422-435.

(18) Gasperi, J.; Wright, S. L.; Dris, R.; Collard, F.; Mandin, C.; Guerrouache, M.; Langlois, V.; Kelly, F. J.; Tassin, B. Microplastics in Air: Are We Breathing It In? Curr. Opin. Environ. Sci. Heal. 2018, 1, $1-5$.

(19) Hale, R. C. Are the Risks from Microplastics Truly Trivial? Environ. Sci. Technol. 2018, 52 (3), 931-931.

(20) Burton, G. A. Stressor Exposures Determine Risk: So, Why Do Fellow Scientists Continue To Focus on Superficial Microplastics Risk? Environ. Sci. Technol. 2017, 51 (23), 13515-13516.

(21) Backhaus, T.; Wagner, M. Microplastics in the Environment: Much Ado about Nothing? A Debate. PeerJPreprints 2019, 0-5.

(22) Koelmans, A. A.; Besseling, E.; Foekema, E.; Kooi, M.; Mintenig, S.; Ossendorp, B. C.; Redondo-Hasselerharm, P. E.; Verschoor, A.; van Wezel, A. P.; Scheffer, M. Risks of Plastic Debris: Unravelling Fact, Opinion, Perception, and Belief. Environ. Sci. Technol. 2017, 51 (20), 11513-11519.

(23) Everaert, G.; Van Cauwenberghe, L.; De Rijcke, M.; Koelmans, A. A.; Mees, J.; Vandegehuchte, M.; Janssen, C. R. Risk Assessment of Microplastics in the Ocean: Modelling Approach and First Conclusions. Environ. Pollut. 2018, 242, 1930-1938.

(24) Adam, V.; Yang, T.; Nowack, B. Toward an Ecotoxicological Risk Assessment of Microplastics: Comparison of Available Hazard and Exposure Data in Freshwaters. Environ. Toxicol. Chem. 2019, 38 (2), 436-447.

(25) Sundt, P.; Schulze, P.-E.; Syversen, F. Sources of Microplastic Pollution to the Marine Environment; 2014; https://www. miljodirektoratet.no/globalassets/publikasjoner/M321/M321.pdf.

(26) Lassen, C.; Hansen, S. F.; Magnusson, K.; Norén, F.; Bloch Hartmann, N. I.; Jensen, P. R.; Nielsen, T. G.; Brinch, A. Microplastics: Occurrence, Effects and Sources of Releases to the Environment in Denmark; The Danish Environmental Protection Agency, 2015; http://orbit.dtu.dk/files/118180844/Lassen_et_al._2015.pdf.

(27) Essel, R.; Engel, L.; Carus, M.; Ah̄rens, R. H. Sources of Microplastics Relevant to Marine Protection in Germany; 2015; https:// www.umweltbundesamt.de/sites/default/files/medien/378/ publikationen/texte 642015 sources of microplastics relevant to marine protection_1.pdf.

(28) Bertling, J.; Bertling, R.; Hamann, L. Kunststoffe in Der Umwelt : Mikro- Und Makroplastik. Ursachen, Mengen, Umweltschicksale, Wirkungen, Lösungsansätze, Empfehlungen. Kurzfassung Der Konsortialstudie.; Oberhausen, 2018; https://www.umsicht.fraunhofer.de/ content/dam/umsicht/de/dokumente/publikationen/2018/ kunststoffe-id-umwelt-konsortialstudie-mikroplastik.pdf.

(29) Magnusson, K.; Eliasson, K.; Fråne, A.; Haikonen, K.; Hultén, J.; Olshammar, M.; Stadmark, J.; Voisin, A. Swedish Sources and Pathways for Microplastics to the Marine Environment. A Review of Existing Data; 2016; https://www.naturvardsverket.se/upload/ miljoarbete-i-samhallet/miljoarbete-i-sverige/regeringsuppdrag/ 2016/mikroplaster/swedish-sources-and-pathways-for-microplasticsto-marineenvironment-ivl-c183.pdf.

(30) Hann, S.; Sherrington, C.; Jamieson, O.; Hickman, M.; Kershaw, P.; Bapasola, A.; Cole, G. Investigating Options for Reducing Releases in the Aquatic Environment of Microplastics Emitted by (but Not Intentionally Added in) Products Final Report; 2018; http://www. eumicroplastics.com/eumpwp/wp-content/uploads/investigatingoptions-eunomia-draft-report-v4-main-report-public.pdf.

(31) Boucher, J.; Friot, D. Primary Microplastics in the Oceans: A Global Evaluation of Sources; 2017; https://portals.iucn.org/library/ sites/library/files/documents/2017-002.pdf.

(32) Horton, A. A.; Walton, A.; Spurgeon, D. J.; Lahive, E.; Svendsen, C. Microplastics in Freshwater and Terrestrial Environments: Evaluating the Current Understanding to Identify the Knowledge Gaps and Future Research Priorities. Sci. Total Environ. 2017, 586, 127-141.

(33) Jambeck, J. R.; Geyer, R.; Wilcox, C.; Siegler, T. R.; Perryman, M.; Andrady, A.; Narayan, R.; Law, K. L. Plastic Waste Inputs from Land into the Ocean. Clim. Chang. 2014 Impacts, Adapt. Vulnerability 2015, 347 (6223), 1655-1732.

(34) Lebreton, L. C. M.; van der Zwet, J.; Damsteeg, J.-W.; Slat, B.; Andrady, A.; Reisser, J. River Plastic Emissions to the World's Oceans. Nat. Commun. 2017, 8, 1-10.

(35) Hoornweg, D.; Bhada-Tata, P. What a Waste: A Global Review of Solid Waste Management; 2012; www.worldbank.org/urban.

(36) Som, C.; Berges, M.; Chaudhry, Q.; Dusinska, M.; Fernandes, T. F.; Olsen, S. I.; Nowack, B. The Importance of Life Cycle Concepts for the Development of Safe Nanoproducts. Toxicology 2010, 269 (23), 160-169.

(37) Gottschalk, F.; Scholz, R. W.; Nowack, B. Probabilistic Material Flow Modeling for Assessing the Environmental Exposure to Compounds: Methodology and an Application to Engineered Nano-TiO2 Particles. Environ. Model. Softw. 2010, 25 (3), 320-332.

(38) Brunner, P. H.; Rechberger, H. Practical Handbook of Material Flow Analysis; Lewis Publishers, 2004; http://thecitywasteproject.files. wordpress.com/2013/03/practical_handbook-of-material-flowanalysis.pdf.

(39) Baccini, P.; Brunner, P. H. Metabolism of the Anthroposphere: Analysis, Evaluation, Design, 2nd Editio.; MIT Press, 2012; www.jstor. org/stable/j.ctt5virm9.

(40) Kawecki, D.; Scheeder, P.; Nowack, B. Probabilistic Material Flow Analysis of Seven Commodity Plastics in Europe. Environ. Sci. Technol. 2018, 52, 9874-9888.

(41) Gottschalk, F.; Sonderer, T.; Scholz, R. W.; Nowack, B. Modeled Environmental Concentrations of Engineered Nanomaterials ( $\mathrm{TiO} 2, \mathrm{ZnO}, \mathrm{Ag}, \mathrm{CNT}$, Fullerenes) for Different Regions. Environ. Sci. Technol. 2009, 43 (24), 9216-9222.

(42) Adam, V.; Nowack, B. European Country-Specific Probabilistic Assessment of Nanomaterial Flows towards Landfilling, Incineration and Recycling. Environ. Sci.: Nano 2017, 4 (10), 1961-1973.

(43) Mahapatra, I.; Sun, T. Y.; Clark, J. R. A.; Dobson, P. J.; Hungerbuehler, K.; Owen, R.; Nowack, B.; Lead, J. Probabilistic Modelling of Prospective Environmental Concentrations of Gold Nanoparticles from Medical Applications as a Basis for Risk Assessment. J. Nanobiotechnology 2015, 13 (1), 1-14. 
(44) Laner, D.; Feketitsch, J.; Rechberger, H.; Fellner, J. A Novel Approach to Characterize Data Uncertainty in Material Flow Analysis and Its Application to Plastics Flows in Austria. J. Ind. Ecol. 2016, 20 (5), 1050-1063.

(45) Gottschalk, F.; Nowack, B. A Probabilistic Method for Species Sensitivity Distributions Taking into Account the Inherent Uncertainty and Variability of Effects to Estimate Environmental Risk Health \& Ecological Risk Assessment. Integr. Environ. Assess. Manage. 2013, 9 (1), 79-86.

(46) Rechberger, H.; Cencic, O.; Frühwirth, R. Uncertainty in Material Flow Analysis. J. Ind. Ecol. 2014, 18 (2), 159-160.

(47) PlasticsEurope. Plastics - The Facts 2015: An Analysis of European Latest Plastics Production, Demand and Waste Data; 2015; http://staging-plasticseurope.idloom.com/download_file/view/478/ 179.

(48) Gasperi, J.; Dris, R.; Bonin, T.; Rocher, V.; Tassin, B. Assessment of Floating Plastic Debris in Surface Water along the Seine River. Environ. Pollut. 2014, 195, 163-166.

(49) Sadri, S. S.; Thompson, R. C. On the Quantity and Composition of Floating Plastic Debris Entering and Leaving the Tamar Estuary, Southwest England. Mar. Pollut. Bull. 2014, 81 (1), $55-60$.

(50) Schubarth, C.; Weibel, F. Die Bodennutzung in Der Schweiz. Resultate Der Arealstatistik; 2013; Vol. 002-0901; https://www.bfs. admin.ch/bfsstatic/dam/assets/348986/master.

(51) Hernandez, E.; Nowack, B.; Mitrano, D. M. Polyester Textiles as a Source of Microplastics from Households: A Mechanistic Study to Understand Microfiber Release During Washing. Environ. Sci. Technol. 2017, 51 (12), 7036-7046.

(52) Sillanpäa, M.; Sainio, P. Release of Polyester and Cotton Fibers from Textiles in Machine Washings. Environ. Sci. Pollut. Res. 2017, 24 (23), 19313-19321.

(53) Hartline, N. L.; Bruce, N. J.; Karba, S. N.; Ruff, E. O.; Sonar, S. U.; Holden, P. A. Microfiber Masses Recovered from Conventional Machine Washing of New or Aged Garments. Environ. Sci. Technol. 2016, 50 (21), 11532-11538.

(54) Pirc, U.; Vidmar, M.; Mozer, A.; Kržan, A. Emissions of Microplastic Fibers from Microfiber Fleece during Domestic Washing. Environ. Sci. Pollut. Res. 2016, 23 (21), 22206.

(55) De Falco, F.; Gullo, M. P.; Gentile, G.; Di Pace, E.; Cocca, M.; Gelabert, L.; Brouta-Agnésa, M.; Rovira, A.; Escudero, R.; Villalba, R.; Mossotti, R.; Montarsolo, A.; Gavignano, S.; Tonin, C.; Avella, M. Evaluation of Microplastic Release Caused by Textile Washing Processes of Synthetic Fabrics. Environ. Pollut. 2018, 236 (XXX), 916-925.

(56) Byrne, M. A.; Kearns, G.; McKenna, C. A Test Chamber Study of the Contribution of Human Body Surfaces to the "Personal Cloud. In Indoor Air 2002, 9th International conference on Indoor Air Quality and Climate; Monterey, California, 2002.

(57) European Communities. European Union Risk Assessment Report: Hexabromocyclododecane CAS-No.: 25637-99-4, EINECSNo.: 247-148-4. Final Report; 2008; https://echa.europa.eu/ documents/10162/661bff17-dc0a-4475-9758-40bdd6198f82.

(58) Yoon, Y. H.; Brimblecombe, P. Clothing as a Source of Fibres within Museums. J. Cult. Herit. 2000, 1 (4), 445-454.

(59) Vigo, T. L.; Lamb, G. E. R.; Kepka, S.; Miller, B. Abrasion and Lint Loss Properties of Fabrics Containing Crosslinked Polyethylene Glycol. Text. Res. J. 1991, 61 (3), 169-176.

(60) Keizer, K.; Lindenberg, S.; Steg, L. The Spreading of Disorder. Science (Washington, DC, U. S.) 2008, 322 (5908), 1681-1685.

(61) Department for Environment Food \& Rural Affairs. Fly-Tipping Statistics for England, 2016/17; 2017; https://assets.publishing.service. gov.uk/government/uploads/system/uploads/attachment data/file/ 652958/Flytipping 201617 statistical release FINAL.pdf.

(62) Friedler, E.; Brown, D. M.; Butler, D. A Study of WC Derived Sewer Solids. Water Sci. Technol. 1996, 33 (9), 17-24.

(63) Spence, K. J.; Digman, C.; Balmforth, D.; Houldsworth, J.; Saul, A.; Meadowcroft, J. Gross Solids from Combined Sewers in Dry
Weather and Storms, Elucidating Production, Storage and Social Factors. Urban Water J. 2016, 13 (8), 773-789.

(64) Goldberg, L. Plastic in Organic Waste in Switzerland: Material Flows and Consequences; University of Zurich, 2018.

(65) Weithmann, N.; Möller, J. N.; Löder, M. G. J.; Piehl, S.; Laforsch, C.; Freitag, R. Organic Fertilizer as a Vehicle for the Entry of Microplastic into the Environment. Sci. Adv. 2018, 4, 1-8.

(66) Faure, F.; De Alencastro, L. F. Recherche de Fragments de Plastique Dans Les Composts et Digestats Industriels; 2016.

(67) WRAP. Report: Plastic Packaging Composition 2011; 2013; .

(68) Eurostat. Population change - Demographic balance and crude rates at national level [demo_gind] http://ec.europa.eu/eurostat/ product code $=$ demo_gind \&language $=$ en $\&$ mode $=$ view $($ accessed Apr 2, 2018).

(69) Scudo, A.; Liebmann, B.; Corden, C.; Tyrer, D.; Kreissig, J.; Warwick, O. Intentionally Added Microplastics in Products; 2017; http://ec.europa.eu/environment/chemicals/reach/pdf/39168 Intentionally added microplastics - Final report 20171020.pdf.

(70) Wik, A.; Dave, G. Occurrence and Effects of Tire Wear Particles in the Environment - A Critical Review and an Initial Risk Assessment. Environ. Pollut. 2009, 157 (1), 1-11.

(71) Besseling, E.; Quik, J. T. K.; Sun, M.; Koelmans, A. A. Fate of Nano- and Microplastic in Freshwater Systems: A Modeling Study. Environ. Pollut. 2017, 220, 540-548.

(72) Blarer, P.; Kull, G. Swiss Litter Report; 2018; www.stoppp.org/ swiss-litter-report.

(73) Erismann, R.; Erismann, S. In(Beach-Litter-Density): Annex B 2016, 1-23.

(74) Federal Office for the Environment FOEN. The Swiss hydrographic network: Network analyses https://www.bafu.admin. $\mathrm{ch} / \mathrm{dam} / \mathrm{bafu} / \mathrm{en} / \mathrm{dokumente/hydrologie/fachinfo-daten/}$ auswertungen_zumgewaessernetz.xlsx.download.xlsx/network analyses.xlsx (accessed Dec 3, 2018).

(75) Le Hyaric, R.; Canler, J. P.; Barillon, B.; Naquin, P.; Gourdon, R. Characterization of Screenings from Three Municipal Wastewater Treatment Plants in the Region Rhône-Alpes. Water Sci. Technol. 2009, 60 (2), 525-531.

(76) Cabernard, L.; Durisch-Kaiser, E.; Vogel, J.-C.; Rensch, D.; Niederhauser, P. AWEL Gewässerschutz. Mikroplastik in Abwasser Und Gewässern. Aqua Gas 2016, 7 (8), 78-85.

(77) Office Fédéral de la Statistique OFS. Bilan de la population résidante permanente par canton, 1991-2017 https://www.bfs. admin.ch/bfsstatic/dam/assets/5886171/master.

(78) Dris, R.; Gasperi, J.; Saad, M.; Mirande, C.; Tassin, B. Synthetic Fibers in Atmospheric Fallout: A Source of Microplastics in the Environment? Mar. Pollut. Bull. 2016, 104 (1-2), 290-293.

(79) Raunemaa, T.; Kulmala, M.; Saari, H.; Olin, M.; Kulmala, M. H. Indoor Air Aerosol Model: Transport Indoors and Deposition of Fine and Coarse Particles. Aerosol Sci. Technol. 1989, 11 (1), 11-25.

(80) Edwards, R. D.; Yurkow, E. J.; Lioy, P. J. Seasonal Deposition of Housedusts onto Household Surfaces. Sci. Total Environ. 1998, 224, 69-80.

(81) Ruotsalainen, R.; Rönnberg, R.; Säteri, J.; Majanen, A.; Seppänen, O.; Jaakkola, J. J. K. Indoor Climate and the Performance of Ventilation in Finnish Residences. Indoor Air 1992, 2 (3), 137145.

(82) Economidou, M.; Atanasiu, B.; Despret, C.; Maio, J.; Nolte, I.; Rapf, O.; Laustsen, J.; Ruyssevelt, P.; Staniaszek, D.; Strong, D.; Zinetti, S. Europe's Buildings Under the Microscope; 2011; http://bpie. eu/wp-content/uploads/2015/10/HR_EU_B_under_microscope study.pdf.

(83) Webster, T. F.; Harrad, S.; Millette, J. R.; Holbrook, R. D.; Davis, J. M.; Stapleton, H. M.; Allen, J. G.; McClean, M. D.; Ibarra, C.; Abdallah, M. A.; Covaci, A. Identifying Transfer Mechanisms and Sources of Decabromodiphenyl Ether (BDE 209) in Indoor Environments Using Environmental Forensic Microscopy. Environ. Sci. Technol. 2009, 43 (9), 3067-3072. 
(84) Mølhave, L.; Schneider, T.; Kjærgaard, S. K.; Larsen, L.; Norn, S.; Jørgensen, O. House Dust in Seven Danish Offices. Atmos. Environ. 2000, 34 (28), 4767-4779.

(85) Talvitie, J.; Heinonen, M.; Pääkkönen, J.-P.; Vahtera, E.; Mikola, A.; Setälä, O.; Vahala, R. Do Wastewater Treatment Plants Act as a Potential Point Source of Microplastics? Preliminary Study in the Coastal Gulf of Finland, Baltic Sea. Water Sci. Technol. 2015, 72 (9), 1495-1504.

(86) Talvitie, J.; Mikola, A.; Setälä, O.; Heinonen, M.; Koistinen, A. How Well Is Microlitter Purified from Wastewater? A Detailed Study on the Stepwise Removal of Microlitter in a Tertiary Level Wastewater Treatment Plant. Water Res. 2017, 109, 164-172.

(87) European Parliament. P8_TA-PROV(2019)0305 Reduction of the Impact of Certain Plastic Products on the Environment; 2019; https:// www.europarl.europa.eu/doceo/document/TA-8-20190305_EN.pdf.

(88) IGSU. Recul Du Littering Dans Toutes Les Régions Du Pays; 2017; https://www.igsu.ch/files/fr_2017-12-05_mm_littering-index. pdf.

(89) Cosmetics Europe. Cosmetics Europe survey shows an $82 \%$ reduction in use of plastic microbeads https://www.cosmeticseurope. eu/news-events/reduction-use-plastic-microbeads (accessed Aug 8, 2017).

(90) European Chemicals Agency. Annex to the Annex XV Restriction Report: Proposal for a Restriction; 2019; https://echa.europa.eu/ documents/10162/decfbb48-7240-9aa2-d0fa-7f18582fce36. 